\title{
Discrimination of Some Gram-negative Bacteria by Direct Probe Mass Spectrometry
}

\author{
By C. S. GUTTERIDGE*† AND D. J. PUCKEY \\ Agricultural Research Council, Meat Research Institute, Langford, Bristol BS18 7DY, \\ Avon, U.K.
}

(Received 28 May 1981)

\begin{abstract}
The technique of direct probe mass spectrometry is described together with its application to the analysis of 50 strains of Gram-negative bacteria representing seven genera. Thirty-six of these strains were analysed in duplicate, and the 72 spectra held in a computer library. The intensities of 63 ions from each of the spectra were analysed by discriminant analysis techniques and all seven groups could be distinguished by as few as six ions. A set of 29 strains, 15 of which were already in the data base, were used as unknowns to challenge the library on two separate occasions. The success rate of these challenges was $97 \%$ and $90 \%$ using the full spectra, but only $72 \%$ and $62 \%$ using the selection of six ions. Possible explanations for this are discussed as well as the scope and limitations of the method as a means of characterizing micro-organisms.
\end{abstract}

\section{INTRODUCTION}

The combination of analytical pyrolysis with gas chromatography (Py-GC) or mass spectrometry (Py-MS) produces data which can be used to discriminate micro-organisms (for reviews, see Irwin, 1979; Gutteridge \& Norris, 1979). With several permanent modifications to a standard mass spectrometer (Meuzelaar \& Kistemaker, 1973), Py-MS can be used for the rapid characterization of bacteria and fungi at a rate of one sample every 5 min (Meuzelaar $e t$ al., 1974; Weyman, 1977). Puckey et al. (1980), following some earlier research by Anhalt \& Fenselau (1975) and Risby \& Yergey $(1976,1978)$, proposed the use of a simpler technique, direct probe mass spectrometry (DPMS), in which samples are thermally degraded adjacent to the ion source of a mass spectrometer using a standard accessory available on most instruments.

The purpose of this paper is to describe the DPMS method in detail and to show its application to the differentiation of bacteria using seven well-defined groups of Gram-negative bacteria. Furthermore, an attempt has been made to establish a data base and match unknowns against it.

\section{METHODS}

Organisms and growth conditions. The 50 strains used in the study are listed in Table 1. All the strains of Citrobacter freundii, Serratia liquefaciens, Pseudomonas sp., Hafnia alvei and Klebsiella pneumoniae E58 and E62 were isolates from meat. The remaining $K$. pneumoniae strains and Acinetobacter calcoaceticus 4406 and 44100 were provided by Dr G. L. French, St. Thomas' Hospital, London. All other cultures were obtained from the relevant collection.

† Present address: Cadbury Schweppes Ltd, Group Research, University of Reading, Whiteknights, Reading RG6 2AD, U.K. 
Table 1. List of strains

\begin{tabular}{|c|c|c|}
\hline Group & Name & Strains* \\
\hline 1 & Citrobacter freundii & $\mathrm{E} 23^{\mathrm{ab}} ; \mathrm{E} 26^{\mathrm{ab}} ; \mathrm{E} 59^{\mathrm{b}} ; \mathrm{E} 82^{\mathrm{a}}$ \\
\hline 2 & Acinetobacter calcoaceticus & $\begin{array}{l}\text { NCTC } 7363^{\mathrm{a}} ; \text { NCTC } 7364^{\mathrm{a}} ; \text { NCTC } 7461^{\mathrm{a}} ; \\
\text { NCTC } 7462^{\mathrm{a}} ; \text { NCTC } 10290^{\mathrm{ab}} ; \text { NCTC } 10291^{\mathrm{ab}} ; \\
4406^{\mathrm{b}} ; 44100^{\mathrm{b}}\end{array}$ \\
\hline 3 & Serratia liquefaciens & $\mathrm{E} 14^{\mathrm{a}} ; \mathrm{E} 15^{\mathrm{b}} ; \mathrm{E} 19^{\mathrm{ab}} ; \mathrm{E} 20^{\mathrm{ab}} ; \mathrm{E} 21^{\mathrm{b}} ; \mathrm{E} 43^{\mathrm{b}}$ \\
\hline 4 & Klebsiella pneumoniae & 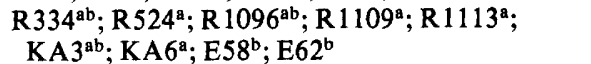 \\
\hline 5 & Pseudomonas sp. & 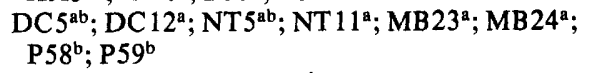 \\
\hline 6 & Proteus morganii & $\begin{array}{l}\text { NCTC } 232^{\mathrm{a}} ; \text { NCTC } 235^{\mathrm{b}} ; \text { NCTC } 1707^{\mathrm{a}} ; \\
\text { NCTC } 2815^{\mathrm{a}} ; \text { NCTC } 5845^{\mathrm{b}} ; \text { NCTC } 10041^{\mathrm{ab}} \text {; } \\
\text { DSM } 30117^{\mathrm{ab}} ; \text { CCM } 680^{\mathrm{b}}\end{array}$ \\
\hline 7 & Hafnia alvei & $\mathrm{E}^{\mathrm{a}} ; \mathrm{E} 5^{\mathrm{a}} ; \mathrm{E} 44^{\mathrm{a}} ; \mathrm{E} 46^{\mathrm{a}} ; \mathrm{E} 57^{\mathrm{b}} ; \mathrm{E} 80^{\mathrm{ab}} ; \mathrm{E} 86^{\mathrm{ab}}$ \\
\hline
\end{tabular}

* $a$, in data base; $b$, used as unknown.

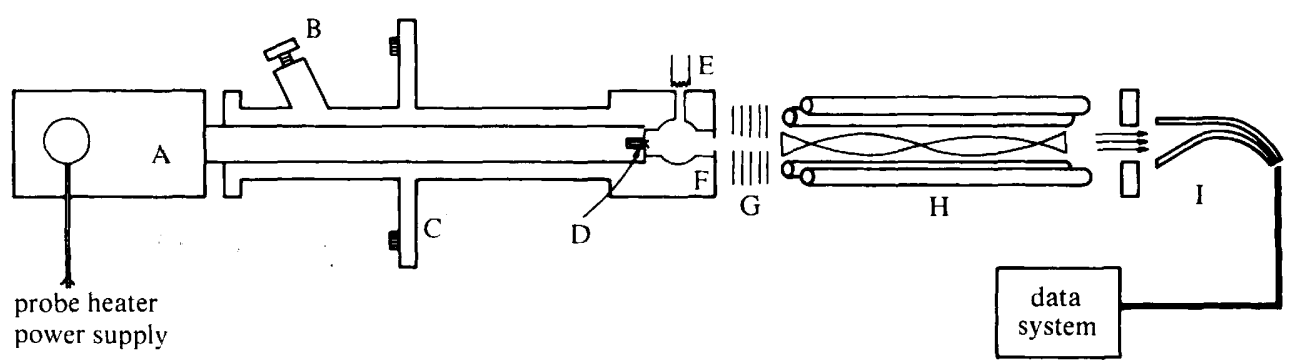

Fig. 1. Direct probe system layout: A, probe; B, valve; C, mass spectrometer housing; D, probe tube; $\mathrm{E}$, ion source; $\mathrm{F}$, ionization region; $\mathrm{G}$, lenses; $\mathrm{H}$, quadrupole rods; $\mathrm{I}$, electron multiplier.

The identification of all the strains was checked using the API 20E system (API Laboratory Products, Farnborough, U.K.). The strains were maintained on nutrient agar (Oxoid) slopes at $4{ }^{\circ} \mathrm{C}$ but cultured for DPMS on plate count agar (Oxoid) at $25^{\circ} \mathrm{C}$ for $24 \mathrm{~h}$.

Preparation of samples for mass spectrometry. Approximately $50 \mu \mathrm{g}$ of whole cells from a single large colony or a few small colonies was taken from the surface of a culture plate using a platinum wire and placed inside a clean quartz-glass tube which was inserted into the stainless steel probe.

Mass spectrometry. The analyses were carried out on a Finnigan 4000 quadrupole instrument coupled to a 2100 data system. The layout of the direct probe insertion system is illustrated schematically in Fig. 1. The mass spectrometer was operated at an electron energy of $25 \mathrm{eV}$, with a multiplier voltage of $1800 \mathrm{~V}$ and a source temperature of $270^{\circ} \mathrm{C}$. After insertion into the high vacuum of the instrument, the probe was temperature programmed at $60^{\circ} \mathrm{C} \mathrm{min}-1$ from ambient to $300^{\circ} \mathrm{C}$. Spectra were recorded on to a magnetic disc over the mass range $m / e$ 33-400 using a $2 \mathrm{~s}$ scan cycle. A full analysis, including the time taken to cool the probe to ambient temperature, took 15 min per sample.

Data analysis. Only 36 of the 50 strains were used to establish a data library but each was analysed in duplicate and the library consisted of 72 'fingerprints'. On two separate occasions the library was challenged by a set of 'unknowns', which contained the remaining 14 strains and 15 that were already included in the data base (see Table 1). Each unknown was analysed once.

A set of intensities for 63 ions $(m / e 53-61,67-74,81-89,91,95-99,108-115,117,124-126,128,129,135$, $136,151,154,158,166,167,185,236,237,239,264,310-313,339)$ was derived for each of the library spectra. The ions chosen were those with the widest range of intensity values across the library. The data were normalized and subjected to canonical variates analysis (MacFie et al., 1978), stepwise discriminant analysis (Emswiler \& Kotula, 1978; Gutteridge et al., 1980) and jacknifing (O'Donnell et al., 1980) to test for discrimination of groups, to select the ions responsible for the differentiation, and to test the stability of the classification. This set of ions represented less than $20 \%$ of the available data, but data reduction was essential to comply with the following numerical constraint necessary for a statistically valid analysis (Dixon, 1975): $N_{\mathrm{v}}<N_{\mathrm{s}}-N_{\mathrm{g}}-1$, where $N_{\mathrm{v}}$ is the number of variables (ions) per sample, $N_{\mathrm{s}}$ is the number of samples and $N_{\mathrm{g}}$ is the number of groups. 
Identification of unknowns was attempted using two methods: (i) by comparison of the full spectrum of an unknown with each library spectrum using the library search routine (Finnigan Corporation, 1978) available on the mass spectrometer data system - this matching procedure reduces the spectrum by a complex algorithm to a set of 'chemically significant' peaks before comparison with similarly abbreviated library entries; (ii) by the use of classification functions derived during stepwise discriminant analysis (Dixon, 1975).

\section{RESULTS}

\section{Ion current profiles and spectra}

As the direct probe was temperature programmed, the total number of ions detected by the mass spectrometer was recorded and displayed as a function of time in an ion current profile. Figure 2 shows typical profiles for duplicate analyses of $C$. freundii E23 and $P$. morganii NCTC 10041. The general shape was the same for each of the organisms studied, with thermal degradation occurring at temperatures above $220^{\circ} \mathrm{C}$ resulting in a large pulse of ions which only subsided when the programme was halted at $300^{\circ} \mathrm{C}$. The probe system has a theoretical limit of $350^{\circ} \mathrm{C}$ but, in practice, $300^{\circ} \mathrm{C}$ is the highest temperature that can be regularly obtained without damaging the vacuum seals of the mass spectrometer. Some profile shapes were complex (e.g. P. morganii NCTC 10041 in Fig. $2 b$ ) but they could not be used to characterize organisms because they seemed to be affected by the size and positioning of the sample within the probe tube.

By trial and error it was found that the most reliable method for obtaining a single spectrum (fingerprint) was to average the total number of ions between the beginning and the amplitude of the pulse (i.e. $220-300^{\circ} \mathrm{C}$ ) and then to subtract a ten-scan background taken from before the pulse. Thus, the actual number of scans per sample varied but the averaging procedure was reproducible from sample to sample because it was applied to the same section of each ion current profile.

Typical examples of averaged spectra are shown in Figs 3 and 4. Ions were detected up to $m / e 400$ but were generally of low intensity above $m / e 200$, except for clusters around $m / e$ 236 and 313 . There were no detectable qualitative differences, as is usually the case with pyrolysis of micro-organisms (Irwin, 1979), so the application of methods for handling quantitative data was essential.

\section{Canonical variates analysis}

Table 2 gives the matrix of Mahalanobis $D^{2}$ distances between the seven group means. Given normality in the statistical sense, $95 \%$ of a population should lie within $5.99 D^{2}$ units of its mean (MacFie et al., 1978), thus Table 2 indicates that all seven groups can be discriminated using the full set of 63 ions.

\section{Stepwise discriminant analysis and jacknifing}

Analysis of the data by stepwise discriminant analysis showed that the seven groups could be distinguished by considering as few as six ions $(m / e 117,82,185,264,70$ and 89 in order of inclusion). The clarity of this data is illustrated in Fig. 5 which is the scatter diagram obtained by plotting the intensity values of $\mathrm{m} / \mathrm{e} 117$ against $\mathrm{m} / \mathrm{e} 82$ for each of the library spectra. The $P$. morganii group was completely distinguished by $m / e 117$ and the Pseudomonas group by $m / e 82$ with the exception of some overlap with one analysis of $A$. calcoaceticus. Figure 5 also illustrates differences in the variability of intensity values from strain to strain within a group. For example, for $P$. morganii $m / e 82$ varies from $14.3-14.9$ but for Pseudomonas it varies from 22.5-32.0.

The stability of the discrimination obtained using the six ions is shown by Table 3 which lists the Mahalanobis $D^{2}$ values for each analysis from each group mean after jacknifing. One analysis ( $S$. liquefaciens E14 2) was mis-classified into the $K$. pneumoniae group but the other 71 samples were reallocated to their original groups. There was no obvious explanation for the 

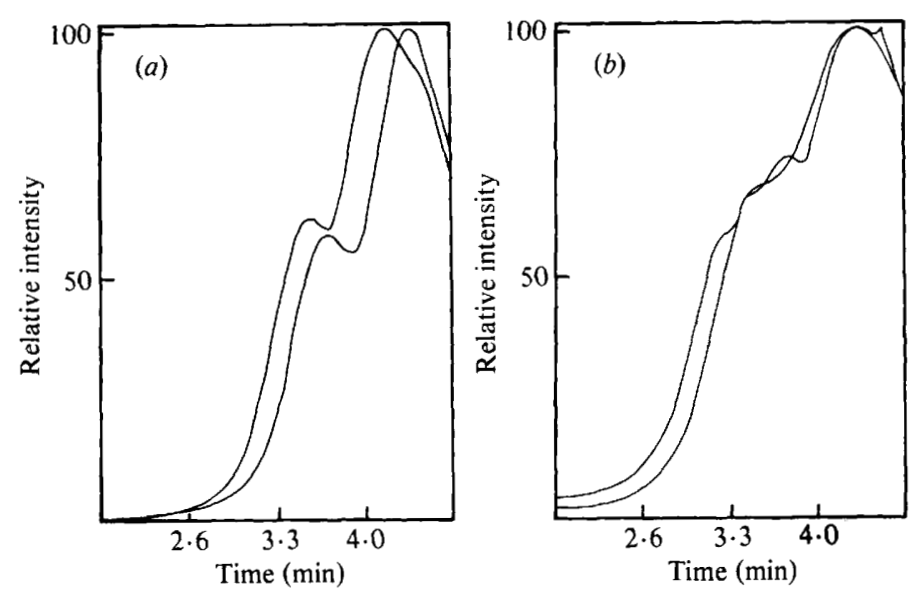

Fig. 2. Typical ion current profiles for duplicate analyses of (a) Citrobacter freundii E23 and (b) Proteus morganii NCTC 10041.

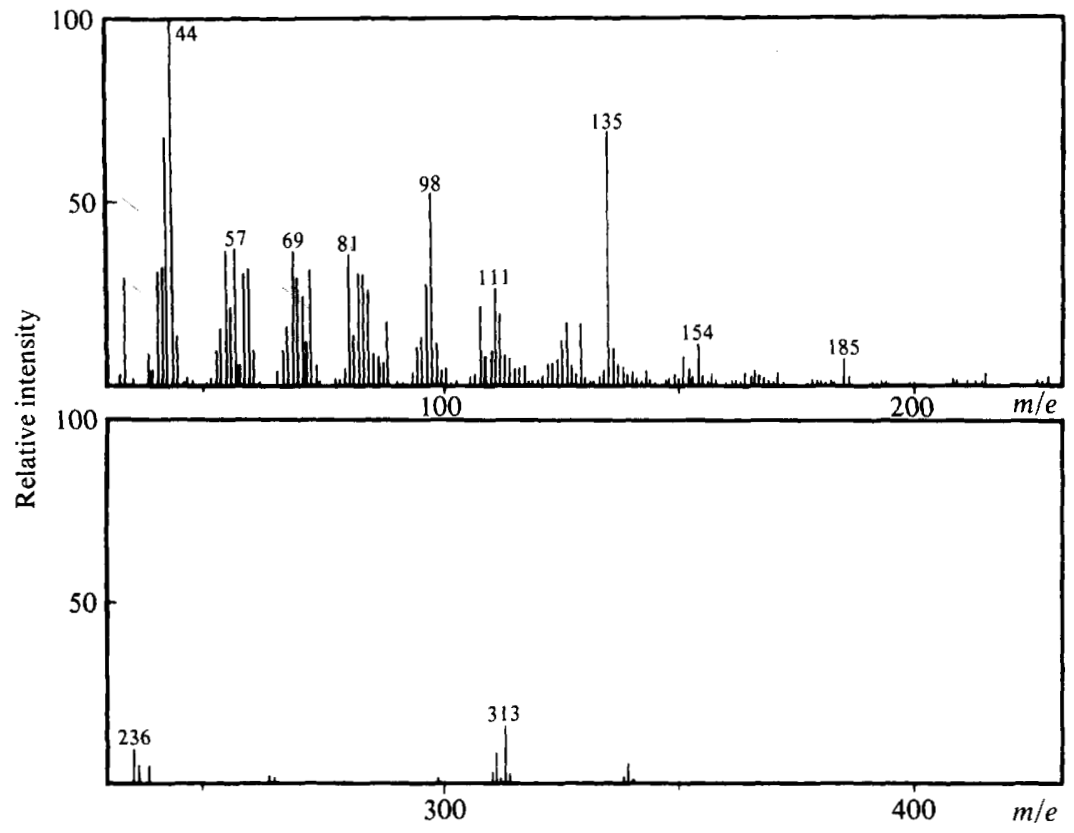

Fig. 3. Mass spectrum of Citrobacter freundii $\mathrm{E} 23$.

mis-classification of E14 2 and it was not deleted from the data base. Examination of the within-group distances reveals that $C$. freundii, $S$. liquefaciens and $H$. alvei are homogeneous in contrast to $A$. calcoaceticus and Pseudomonas, whilst $K$. pneumoniae R1096 and $P$. morganii NCTC 10041 were outliers of their respective groups.

\section{Computer matching of unknown spectra}

The results of the two challenges are presented in Table 4. The use of the full spectrum produced better results $(28 / 29$ and $26 / 29)$ than using classification functions based on the six selected ions $(21 / 29$ and 18/29). Challenge 1 was presented 7 weeks after the creation of the 


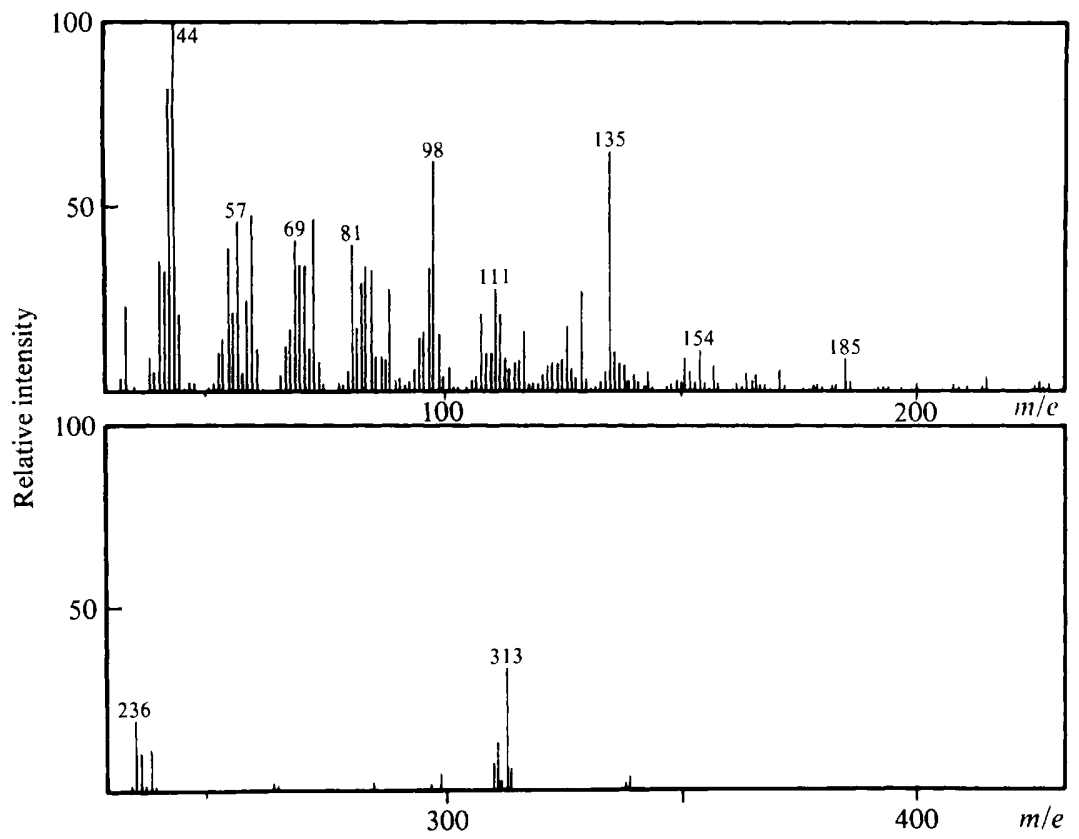

Fig. 4. Mass spectrum of Proteus morganii NCTC 10041.

Table 2. Matrix of Mahalanobis distances between all seven groups

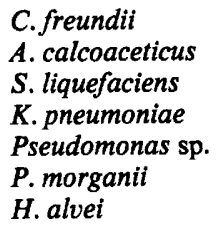

C. freundii

A. calcoaceticus

K. pneumoniae

P. morgani

H. alvei
(1) -

(2) $53-$

(3) $56 \quad 62$

$\begin{array}{llll}\text { (4) } \quad 88 & 74 & 56\end{array}$

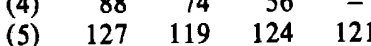

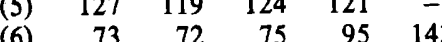

$\begin{array}{lllllll}\text { (7) } & 48 & 63 & 61 & 75 & 115 & 70\end{array}$
(1)
(3)
(4)
(5)
(6)

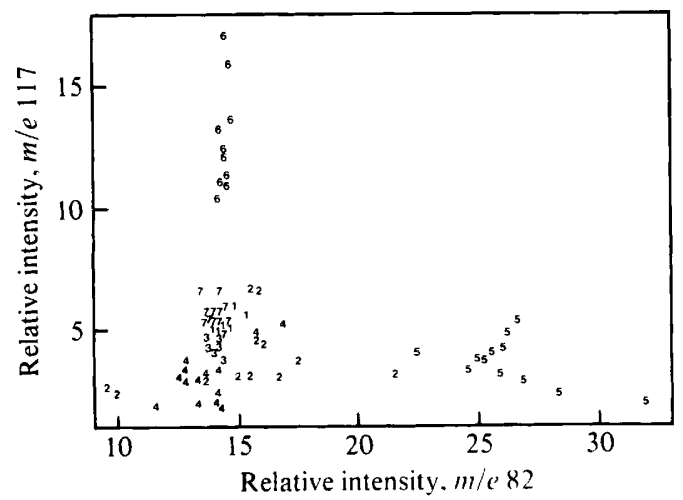

Fig. 5. Scatter diagram of the relative intensities of ions of $m / e 117$ versus $m / e$ 82: 1 , Citrobacter freundii; 2, Acinetobacter calcoaceticus; 3, Serratia liquefaciens; 4, Klebsiella pneumoniae; 5 , Pseudomonas sp.; 6, Proteus morganii; 7, Hafnia alvei. 
Table 3. Jacknifed classification using six selected ions

Group, strain
and duplicate
C. freundii
E23 1
E23 2
E26 1
E26 2
E82 1
E82 2

\begin{tabular}{rrrrrrr}
\multicolumn{6}{c}{ Jacknifed Mahalanobis $D^{2}$ from group } \\
\hline 1 & 2 & 3 & 4 & 5 & 6 & 7 \\
& & & & & & \\
6 & 60 & 11 & 26 & 173 & 72 & 12 \\
1 & 79 & 19 & 23 & 214 & 93 & 17 \\
2 & 99 & 27 & 43 & 194 & 84 & 7 \\
3 & 112 & 38 & 48 & 228 & 94 & 11 \\
1 & 77 & 22 & 28 & 214 & 92 & 15 \\
2 & 93 & 29 & 29 & 239 & 107 & 18
\end{tabular}

2. A. calcoaceticus NCTC 7363 NCTC 73632 NCTC 73641 NCTC 73642 NCTC 74611 NCTC 74612 NCTC 74621 NCTC 74622 NCTC 102901 NCTC 102902 NCTC 102911

\begin{tabular}{|c|c|c|c|c|c|c|}
\hline 81 & 20 & 31 & 47 & 132 & 113 & 104 \\
\hline 142 & 25 & 105 & 117 & 147 & 185 & 178 \\
\hline 63 & 11 & 26 & 38 & 158 & 105 & 87 \\
\hline 74 & 14 & 29 & 52 & 127 & 98 & 89 \\
\hline 110 & 5 & 77 & 93 & 162 & 139 & 137 \\
\hline 100 & 2 & 65 & 80 & 166 & 129 & 127 \\
\hline 69 & 24 & 52 & 64 & 222 & 122 & 90 \\
\hline 64 & 31 & 50 & 59 & 244 & 119 & 85 \\
\hline 107 & 9 & 75 & 76 & 227 & 158 & 148 \\
\hline 181 & 52 & 159 & 121 & 454 & 294 & 270 \\
\hline 106 & 8 & 75 & 96 & 183 & 100 & 134 \\
\hline 125 & 16 & 85 & 127 & 153 & 89 & 137 \\
\hline
\end{tabular}

3. S. liquefaciens

$\begin{array}{ll}\text { E14 1 } & 20 \\ \text { E14 } 2 & 22 \\ \text { E19 } 1 & 37 \\ \text { E19 2 } & 28 \\ \text { E20 } 1 & 28 \\ \text { E20 2 } & 22\end{array}$

$\begin{array}{rrrrrrl}20 & 42 & 9 & 13 & 172 & 75 & 39 \\ 22 & 57 & 14 & 4 & 224 & 104 & 51^{*} \\ 37 & 57 & 4 & 29 & 139 & 77 & 40 \\ 28 & 59 & 2 & 24 & 142 & 84 & 32 \\ 28 & 57 & 4 & 29 & 131 & 83 & 30 \\ 22 & 53 & 1 & 23 & 142 & 76 & 28\end{array}$

4. K. pneumoniae R334 1

R334 2

R524 1

R524 2

R 10961

R10962

R1109 1

R11092

R1113

R11132

KA3 1

KA3 2

KA6 1

KA6 2

$\begin{array}{rrr}37 & 66 & 20 \\ 43 & 92 & 25 \\ 39 & 43 & 17 \\ 39 & 59 & 18 \\ 20 & 99 & 25 \\ 29 & 126 & 41 \\ 33 & 55 & 21 \\ 40 & 52 & 20 \\ 35 & 47 & 14 \\ 51 & 51 & 29 \\ 41 & 73 & 23 \\ 27 & 59 & 8 \\ 22 & 71 & 14 \\ 50 & 100 & 25\end{array}$

Pseudomonas sp.

DC5 1

DC5 2

DC12 1

DC12 2

NT5 1

NT5 2

NT 111

NT11 2

MB23 1

MB23 2

MB24 1

MB24 2

$\begin{array}{rlll}\mathbf{1} & \mathbf{2 3 7} & 151 & \mathbf{7 4} \\ \mathbf{3} & 270 & 163 & \mathbf{8 1} \\ \mathbf{5} & 229 & 128 & \mathbf{7 4} \\ \mathbf{2} & \mathbf{2 4 5} & 136 & \mathbf{7 6} \\ \mathbf{1 4} & \mathbf{2 5 7} & 139 & \mathbf{5 2} \\ \mathbf{2 8} & \mathbf{2 8 3} & 160 & 64 \\ \mathbf{4} & \mathbf{2 3 1} & \mathbf{1 4 7} & \mathbf{6 9} \\ \mathbf{3} & 235 & 150 & \mathbf{7 7} \\ \mathbf{3} & 225 & 129 & 68 \\ \mathbf{7} & 271 & 166 & 95 \\ \mathbf{3} & 267 & 143 & \mathbf{8 2} \\ \mathbf{2} & 209 & 121 & 55 \\ \mathbf{2} & \mathbf{2 3 4} & 135 & \mathbf{5 3} \\ \mathbf{8} & \mathbf{2 5 1} & 186 & \mathbf{8 4}\end{array}$

6. P. morganii

NCTC 232

NCTC 2322

223

$\begin{array}{lll}173 & 161 & 248\end{array}$

$\begin{array}{llll}211 & 160 & 156 & 245\end{array}$

$\begin{array}{llll}211 & 191 & 177 & 282\end{array}$

$\begin{array}{llll}249 & 235 & 216 & 342\end{array}$

$\begin{array}{llll}212 & 168 & 154 & 245\end{array}$

$\begin{array}{llll}199 & 154 & 138 & 223\end{array}$

$\begin{array}{llll}359 & 346 & 336 & 422\end{array}$

$\begin{array}{llll}201 & 175 & 151 & 225\end{array}$

$\begin{array}{llll}213 & 163 & 141 & 227\end{array}$

$\begin{array}{llll}170 & 134 & 110 & 190\end{array}$

$\begin{array}{llll}190 & 140 & 131 & 222\end{array}$

$\begin{array}{llll}226 & 180 & 152 & 245\end{array}$

$\begin{array}{rrr}\mathbf{1} & 171 & 185 \\ \mathbf{2} & 156 & 171 \\ \mathbf{1 3} & 148 & 159 \\ \mathbf{2 0} & 164 & 185 \\ \mathbf{1} & 144 & 171 \\ \mathbf{2} & 139 & 163 \\ \mathbf{5 2} & 332 & 316 \\ \mathbf{1 2} & 177 & 171 \\ \mathbf{6} & 154 & 177 \\ \mathbf{1 2} & 133 & 139 \\ \mathbf{9} & 127 & 149 \\ 7 & 160 & 182\end{array}$

NCTC 17071

$\begin{array}{rrrrrrr}61 & 99 & 58 & 114 & 144 & 5 & 44 \\ 109 & 111 & 84 & 156 & 130 & 4 & 85 \\ 81 & 113 & 78 & 141 & 146 & 2 & 61\end{array}$




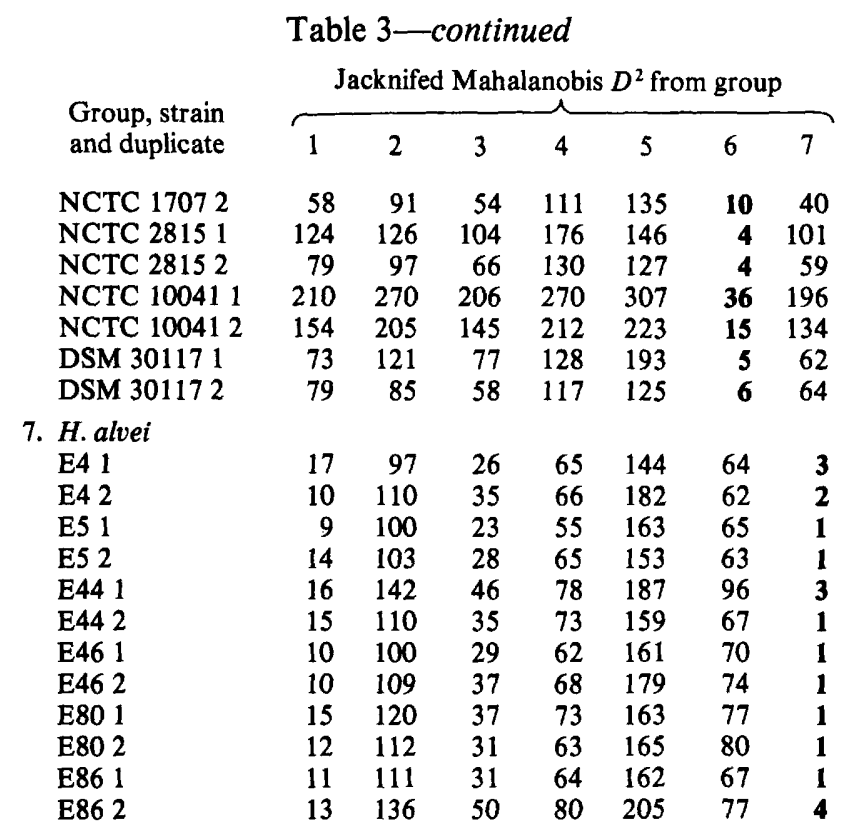

The distances in bold type indicate group allocation on jacknifing.

* Indicates sample mis-identified on jacknifing.

data base and challenge 2 after a further 2 weeks, which suggests that the instrumentation was stable for this time.

\section{DISCUSSION}

The DPMS system used in this research is a substantial improvement on the method we have previously described (Puckey et al., 1980) which was based on an LKB 9000 magnetic sector instrument. The use of a rapid scanning quadrupole and an integrated data system confer major advantages in the processing of the fingerprints, although the discriminant analysis procedures still have to be carried out on an off-line main frame computer. The use of lower electron energies $(25 \mathrm{eV}$ rather than $70 \mathrm{eV})$ produced an improvement in the specificity of the spectra and thus in their usefulness for discriminating micro-organisms, an observation which agrees with results from Curie-point Py-MS (Posthumus et al., 1974). The only possible disadvantage of the Finnigan-based DPMS system compared with the magnetic sector machine is the reduced size of high mass fragments $(>m / e 400)$ which were found by both Anhalt \& Fenselau (1975) and Puckey et al. (1980). Since the limiting step with these methods is data processing, a reduction in the available information in favour of a more integrated and rapid approach to data handling is a sensible compromise.

The seven groups of Gram-negative bacteria that were differentiated did not represent a real identification problem because they can be easily distinguished by conventional techniques, but most pyrolysis studies have concentrated on the species or sub-species levels (e.g. Borst $e t$ al., 1978; Emswiler \& Kotula, 1978) and it is important to show that these techniques can operate successfully at higher levels. Most published studies have only considered discrimination of micro-organisms (e.g. Cone \& Lechowich, 1970; Stern et al., 1979), but Wieten et al. (1981) have shown that Py-MS can be used for identification of clinical mycobacteria and this data base has been stable for more than 1 year. Although our study was only conducted over 2 months, it shows that recognition of a wider variety of organisms 
Table 4. Results of matching unknowns against library

\begin{tabular}{|c|c|c|c|c|}
\hline \multirow[b]{2}{*}{ Strain } & \multicolumn{2}{|c|}{ Challenge 1} & \multicolumn{2}{|c|}{ Challenge 2} \\
\hline & Full spectra & $\begin{array}{l}\text { Classification } \\
\text { functions }\end{array}$ & Full spectra & $\begin{array}{l}\text { Classification } \\
\text { functions }\end{array}$ \\
\hline \multicolumn{5}{|l|}{ C. freundii } \\
\hline E23 & + & + & + & - \\
\hline E26 & + & + & + & - \\
\hline E59 & + & + & + & - \\
\hline \multicolumn{5}{|l|}{ A. calcoaceticus } \\
\hline NCTC 10290 & + & + & + & + \\
\hline NCTC 10291 & + & + & + & + \\
\hline 4406 & + & + & - & + \\
\hline 44100 & + & - & + & - \\
\hline \multicolumn{5}{|l|}{ S. liquefaciens } \\
\hline E15 & + & - & + & - \\
\hline E19 & + & + & + & + \\
\hline E20 & + & + & + & + \\
\hline E21 & + & + & + & + \\
\hline $\mathrm{E} 43$ & - & + & + & + \\
\hline \multicolumn{5}{|l|}{ K. pneumoniae } \\
\hline R334 & + & + & + & + \\
\hline R1096 & + & + & + & + \\
\hline $\mathrm{KA3}$ & + & - & + & - \\
\hline E58 & + & - & - & - \\
\hline E62 & + & + & - & + \\
\hline \multicolumn{5}{|l|}{ Pseudomonas sp. } \\
\hline DC5 & + & + & + & + \\
\hline NT5 & + & + & + & + \\
\hline P58 & + & + & + & - \\
\hline P59 & + & + & + & + \\
\hline \multicolumn{5}{|l|}{ P. morganii } \\
\hline NCTC 235 & + & + & + & + \\
\hline NCTC 5845 & + & + & + & + \\
\hline NCTC 10041 & + & + & + & + \\
\hline DSM 30117 & + & - & + & + \\
\hline CCM 680 & + & + & + & + \\
\hline \multicolumn{5}{|l|}{ H. alvei } \\
\hline E57 & + & - & + & - \\
\hline$E 80$ & + & - & + & - \\
\hline E86 & + & - & + & - \\
\hline Total & $28 / 29$ & $21 / 29$ & $26 / 29$ & $18 / 29$ \\
\hline
\end{tabular}

is possible through the use of computerized data libraries. It remains to be proven that this is possible over long periods (many years) and the reduction in the number of successful matches during the second challenge suggests that the performance of the data base did deteriorate with time. The use of dedicated instrumentation and regular monitoring of mass spectrometer performance by the use of standard samples may provide a solution to this important problem.

The data analysis methods used here have been applied mainly to Py-GC data (Emswiler \& Kotula, 1978; O'Donnell et al., 1980) where there are usually fewer variables per sample than in DPMS or Py-MS. Consequently, with mass spectrometry, pre-processing methods for data reduction are essential. In this study, ions were selected purely on the basis of overall variability, and a more statistically based approach to data reduction, such as those of Eshuis et al. (1977) and Blomquist et al. (1979), may prove beneficial. Nevertheless, there was enough information in the set of 63 ions to distinguish the seven groups. 
Further reduction of this data set using stepwise discriminant analysis showed that six ions could distinguish the groups but classification functions based on these ions could not be used to recognize unknowns, in contrast to library searching of the full spectra. This indicates that the six ions selected provided only one solution to the problem of discriminating the seven groups and this six ion solution was not sufficiently stable to allow identification of unknowns. This implies that either (i) ions with good discriminating properties were not included in the set of 63 presented for discriminant analysis or (ii) that classification functions are too data-specific to be useful for identification purposes. Despite these problems there is a role for stepwise discriminant analysis for testing the stability of data bases and the 'goodness of fit' of individual strains, but the development of improved methods for recognition using this type of quantitative data will require further investigation.

Comparison of the canonical variates analysis results (Table 2) with a similar exercise conducted with Py-GC (MacFie et al., 1978) shows that DPMS produces better discrimination at the genus level, which is further evidence for the technical superiority of Py-MS techniques over Py-GC techniques (Meuzelaar \& Kistemaker, 1973). It would be wrong to regard DPMS as competitive with Curie-point Py-MS since they produce essentially the same type of data, but some comparisons are necessary to assess their potential usefulness.

The pyrolysis methods employed in the two techniques are radically different, and although the DPMS temperature programme is reproducible the starting temperature and the point at which the analysis is halted are not easily controlled. It would be a considerable advantage to be able to programme the probe to temperatures well in excess of $300^{\circ} \mathrm{C}$ until no breakdown products could be detected, but this is not possible with the mass spectrometer used. Consequently, the short term, day to day, reproducibility of DPMS data $(10-12 \%$, unpublished results) is not as good as for equivalent Py-MS data (6-8\%, Windig et al., 1979) although the higher mass fragments which can be observed with DPMS may make the spectra more characteristic of particular micro-organisms. The analysis times per sample are longer than for Py-MS (Meuzelaar et al., 1977) and thus the automated Curie-point pyrolysis mass spectrometer is the preferred method for routine fingerprinting of large numbers of samples. However, until purpose-built instrumentation is commercially available the use of DPMS will make pyrolysis techniques more accessible and will encourage a rapid development of data processing methods and procedures for recognizing unknown strains.

\section{REFERENCES}

Anhalt, J. P. \& Fenselau, C. (1975). Identification of bacteria using mass spectrometry. Analytical Chemistry 47, 219-225.

Blomquist, G., Johansson, E., Söderström, B. \& WoLD, S. (1979). Data analysis of pyrolysis chromatograms by means of Simca pattern recognition. Journal of Analytical and Applied Pyrolysis 1, 53-65.

Borst, J., van DeR Snee-EnkelaAR, A. C. \& MeuzelaAR, H. L. C. (1978). Typing of Neisseria gonorrhoeae by pyrolysis mass spectrometry. Antonie van Leeuwenhoek 44, 253.

Cone, R. D. \& Lechowich, R. V. (1970). Differentiation of Clostridium botulinum types A, B and E by pyrolysis gas-liquid chromatography. Applied Microbiology 19, 138-145.

Dixon, W. J. (1975). Biomedical Computer Programs. Los Angeles: University of California Press.

Emswiler, B. S. \& Kotula, A. W. (1978). Differentiation of Salmonella serotypes by pyrolysis gasliquid chromatography. Applied and Environmental Microbiology 35, 97-104.
Eshuis, W., Kistemaker, P. G. \& MeuzelaAR, H. L. C. (1977). Some numerical aspects of reproducibility and specificity. In Analytical Pyrolysis, pp. 151-166. Edited by C. E. R. Jones \& C. A. Cramers. Amsterdam: Elsevier.

Finnigan Corporation (1978). MSDS System Reference Manual. Sunnyvale, California: Finnigan Corporation.

GutTeridge, C. S. \& NorRIS, J. R. (1979). The application of pyrolysis techniques to the identification of micro-organisms. Journal of Applied Bacteriology 47, 5-43.

GutTeridge, C. S., Mackey, B. M. \& Norris, J. R. (1980). A pyrolysis gas-liquid chromatography study of Clostridium botulinum and related organisms. Journal of Applied Bacteriology 49, 165-174.

IRWIN, W. J. (1979). Analytical pyrolysis - an overview. Journal of Analytical and Applied Pyrolysis 1, 3-25.

MacFie, H. J. H., GutTeridge, C. S. \& Norris, J. R. (1978). Use of canonical variates analysis in differentiation of bacteria by pyrolysis gas-liquid 
chromatography. Journal of General Microbiology 104, 67-74.

MeuzelaAR, H. L. C. \& Kistemaker, P. G. (1973). A technique for fast and reproducible fingerprinting of bacteria by pyrolysis mass spectrometry. Analytical Chemistry 45, 587-590.

Meuzelaar, H. L. C., Kistemaker, P. G. \& Posthumus, M. A. (1974). Recent advances in pyrolysis mass spectrometry of complex biological materials. Biomedical Mass Spectrometry 1, 312319.

Meuzelaar, H. L. C., Kistemaker, P. G., Eshuis, W. \& ENGEL, H. W. B. (1977). Progress in automated and computerised characterisation of micro-organisms by pyrolysis mass spectrometry. In Rapid Methods and Automation in Microbiology, pp. 225-230. Edited by S. W. B. Newsom \& H. H. Johnston. Oxford: Learned Information Ltd.

O'Donnell, A. G., MACFIE, H. J. H. \& Norris, J. R. (1980). An investigation of the relationship between Bacillus cereus, Bacillus thuringiensis and Bacillus mycoides using pyrolysis gas-liquid chromatography. Journal of General Microbiology 119 , 189-194.

Posthumus, M. A., Boerboom, A. J. H. \& MeuzelaAR, H. L. C. (1974). Analysis of biopolymers by Curie-point pyrolysis in direct combination with low voltage electron impact ionisation mass spectrometry. In Advances in Mass Spectrometry, vol. 6, pp. 397-402. Edited by A. R. West. London: Heyden.

Puckey, D. J., Norris, J. R. \& Gutteridge, C. S.
(1980). Discrimination of micro-organisms using direct probe mass spectrometry. Journal of General Microbiology 118, 535-538.

RisBY, T. H. \& YERGEY, A. L. (1976). Identification of bacteria using linear programmed thermal degradation mass spectrometry. The preliminary investigation. Journal of Physical Chemistry 80, 2839-2845.

RisBy, T. H. \& YeRgey, A. L. (1978). Linear programmed thermal degradation mass spectrometry. Analytical Chemistry 50, 326A-334A.

Stern, N. J., Kotula, A. W. \& Pierson, M. D. (1979). Differentiation of selected Enterobacteriaceae by pyrolysis gas-liquid chromatography. Applied and Environmental Microbiology 38, 1098-1102.

Weyman, A. C. M. (1977). The application of Curie-point pyrolysis mass spectrometry in fungal taxonomy. In Analytical Pyrolysis, pp. 225-233. Edited by C. E. R. Jones \& C. A. Cramers. Amsterdam: Elsevier.

Wieten, G., Haverkamp, J., Meuzelaar, H. L. C., Engel, H. W. B. \& Berwald, L. G. (1981). Pyrolysis mass spectrometry: a new method to differentiate between the mycobacteria of the "tuberculosis complex' and other mycobacteria. Journal of General Microbiology 122, 109-118.

Windig, W., Kistemaker, P. G., Haverkamp, J. \& MeuzelaAR, H. L. C. (1979). The effects of sample preparation, pyrolysis and pyrolysate transfer conditions on pyrolysis mass spectra. Journal of Analytical and Applied Pyrolysis 1, 39-52. 